\title{
Frecuency of antigens and alloantibodies of Diego system in blood
}

\author{
Fernando B. Góngora ${ }^{1,2}$ and Rosa F. Chiriboga-Ponce ${ }^{3,4}$ \\ ${ }^{1}$ Red Cross National Blood Center; ${ }^{2}$ Ministerio de Salud Pública del Ecuador; ${ }^{3}$ Center of Research for health in Latin America, Pontificia Universidad \\ Católica del Ecuador; ${ }^{4}$ Faculty of Medicine, Clinical Biochemistry Degree Program, Pontificia Universidad Católica del Ecuador, Quito, Ecuador
}

\begin{abstract}
Introduction: The Diego blood group is an irregular blood system which has been involved in cases of hemolytic disease of the newborn and post transfusion reactions, in this system have been identified 22 erythrocyte antigens, among which the pair Dia $\mathrm{Di}^{\mathrm{b}}$ is the most important because those have the most immunogenic potential. Objective: This research aims to determine the frequency of antigen $\mathrm{Di}^{\mathrm{a}}$ and their respective alloantibody in the Ecuadorian population. Methods: It was performed a simple random sampling in the donor population, being later tested tube agglutination by the presence or absence of the antigen and its alloantibody $\mathrm{Di}{ }^{\mathrm{a}}$ applying gel agglutination technique. Results: It was observed an antigen prevalence of $25 \%$ against a $6.09 \%$ of percentage alloimmunization due to $\mathrm{Di}^{\mathrm{a}}$ antigen, without significant differences between men and women and these being independent of the age and origin of the donor, showing that there are some Diego positive cases in Ecuadorian population as probably cases of transfusional alloinmunization or due to fetal-maternal alloinmunization. Conclusions and Recommendations: The frequency distribution of antigens and alloantibodies from the Diego blood group is almost uniform in the population, due presumably to the high incidence of miscegenation in our country. Therefore it becomes vitally important the implementation of this blood system inside the protocols of irregular antibodies identification in Ecuadorian blood banks.
\end{abstract}

KEY WORDS: Diego system. Blood donors. Alloinmunization. Dia antigen.

\section{Introduction}

Within the classification of blood groups, the Diego antigen or factor was the tenth to be discovered among the red blood cell antigens ${ }^{1}$. After this finding by Miguel Layrisse and Tuli Arends, identification of this antigen gained importance, with several studies being conducted, especially in indigenous groups of the Venezuelan and Caribbean populations, and a prevalence of $35.54 \%$ being found. This alerted Latin American countries about the existence of a new red blood cell antigen able to elicit the production of antigens that cause hemolytic disease of the newborn (HDNB) ${ }^{1,2}$.

Subsequent studies demonstrated that the Diego $\mathrm{Di}^{\mathrm{a}}$ antigen, in spite of having a low incidence in the Caucasian population, can produce alloimmunization and development of anti-Di ${ }^{\mathrm{a}}$ antibodies that cause post-transfusional hemolytic reactions ${ }^{3}$. One of the particular characteristics of this antibody is that it can be present as an immune response or naturally and cause an immediate hemolytic reaction.

Many times, alloimmunization by red blood cell antigens of the Diego system goes unnoticed, and it is until transfusional reactions or fatal hemolysis occur in neonates when its existence is determined in compromised patients, thus giving raise to doubt about the percentage of the population that is inadvertently exposed to these antigens ${ }^{3-5}$.

In Ecuador, information about the presence of Diego system antigens and alloantibodies is not known, and even more when it comes to studies on the prevalence of this system, about which information is nearly inexistent. Similarly, the incidence of HDNB cases caused

\section{Correspondence:}

Rosa F. Chiriboga-Ponce

Avda. de la prensa 48-100

Date of reception: 07-07-2016

C.P. EC170103, Quito, Ecuador

E-mail: rfchiriboga@ puce.edu.ec
Date of acceptance: 18-08-2016

DOI://dx.doi.org/10.24875/GMM.M18000105
Gac Med Mex. 2018;154:8-12

Contents available at PubMed www.gacetamedicademexico.com 
by irregular blood systems is unknown, which opens the question on the prevalence of this blood system in the country, taking into account that the population is not significantly or anthropologically different from the rest of the Latin population of the continent. Furthermore, in the transfusional field, reactions produced by antigens of the $\mathrm{ABO}$ and Rh system have been given more attention, wrongly leaving aside the reactions produced by irregular antibodies, including those of the Diego system ${ }^{6,7}$.

All investigations related to this antigen provide the scientific bases for including its identification in regular blood typing and pre-transfusion tests, especially in populations with significant prevalence and indigenous population. In Ecuador, the National Institute of Statistics and Censuses (INEC - Instituto Nacional de Estadística y Censos) establishes that there is an elevated incidence of indigenous population (approximately one million inhabitants), which determines for $7 \%$ of the population to be considered ethnic population $^{8}$; therefore, Diego antigen screening should be considered, especially in women of childbearing age and prior to blood transfusions.

\section{Methods}

A cross-sectional, descriptive observational study with simple random sampling was carried out for the determination of both $\mathrm{Di}^{\mathrm{a}}$ antigens and anti-Di alloantibodies. Sample collection: pilot tubes obtained during the donation process were used and maintained in the serum bank of the blood center triage station. All donors signed an informed consent authorizing the performance of "all the required tests" prior to the use of the blood products (FOS.10). Reagents used: Bio-Rad ID-Dia (Diego)-positive; 0.8\% suspension, Id. 05980; ID anti-Dia dried-monoclonal antibody; Bio-Rad albumin 30\% batch 11840 and: Bio-Rad DiaClon Coombs Serum Green, Id. 14060 and Coombs-Gel Grifols cards Id. 3009280. Sample processing: the in-tube technique was used and, by means of agglutination reaction, the presence or absence of $\mathrm{Di}^{\mathrm{a}}$ antigen was determined. For alloantibody detection, serum and the gel technique were used for higher sensitivity. Statistical analysis: an Excel-based registry was maintained, where the following data were captured: code, age, gender, place of origin, results, SABO blood group, $\mathrm{Di}^{\mathrm{a}}$ antigen and anti-Di $\mathrm{i}^{\mathrm{a}}$ antibodies, with coding being maintained for analysis with descriptive statistics, whereas for the between-variables relationship, the chi-square statistical test was used².

\section{Results}

A total of 383 donors originating from 22 provinces of the Ecuadorian territory were analyzed, with a prevalence of $\mathrm{Di}^{\mathrm{a}}$ antigen of $25 \%$ being determined, distributed in 22 provinces, with the Pichincha, Loja, Manabí and El Oro provinces showing the highest prevalence of this antigen; other provinces of the central mountain range that showed high prevalence were Chimborazo $(9 \%)$, Tungurahua $(8 \%)$ and Cotopaxi (7\%). The Manabí province also stands out, with 10\% (Fig. 1).

The relationship between $\mathrm{Di}^{\mathrm{a}}$ antigen and donor gender was not significant ( $p>0.05$ ), with a prevalence of $35 \%$ being identified in females and $20 \%$ in males.

A percentage of alloimmunization of $6.09 \%$ was identified in the population of Ecuadorian donors (for this study, 18 provinces were included in the random sampling). Dia antigen-alloimmunized individuals were found in 12 of the 18 participating provinces. Manabí had the highest prevalence with $31.32 \%$ alloimmunization, followed by Guayas with $13.64 \%$ and Los Ríos and Pichincha with $9.09 \%$ each (Fig. 2).

There is a higher alloimmunization rate in females $(6.30 \%)$ than in males $(5.52 \%)$; this may be due to predisposing factors such as previous pregnancies or transfusions. With regard to age, anti-Dia was found to be distributed in all age groups; however, this relationship of variables was not significant $(p>0.05)$.

\section{Discussion}

The prevalence of antigens of the Diego system, specifically of the $\mathrm{Di}^{\mathrm{a}}$ or $\mathrm{Di}^{1}$ racial antigen, is almost inexistent in Afro-American and Caucasian populations, but it is relatively common in the Latin American indigenous population ${ }^{3,9}$. In the present study, a prevalence of $\mathrm{Di}^{\mathrm{a}}$ antigen of $25 \%$ was found in Ecuadorian blood donors, in contrast with a study carried out in Guatemala, where total prevalence of Diego $\mathrm{Di}^{1}$ antigen was established at $7.5 \%$ in blood donors, distributed between the Mestizo and indigenous populations, with a prevalence of $12.99 \%$ and $3.90 \%$, respectively ${ }^{10}$. The present investigation does not allow determining ethnic differences because in the donation form there is not a question specifying donor's ethnicity. However, according to INEC, in Ecuador there is a high incidence of indigenous population, approximately one million inhabitants, which determines for $7 \%$ of the population to be considered 


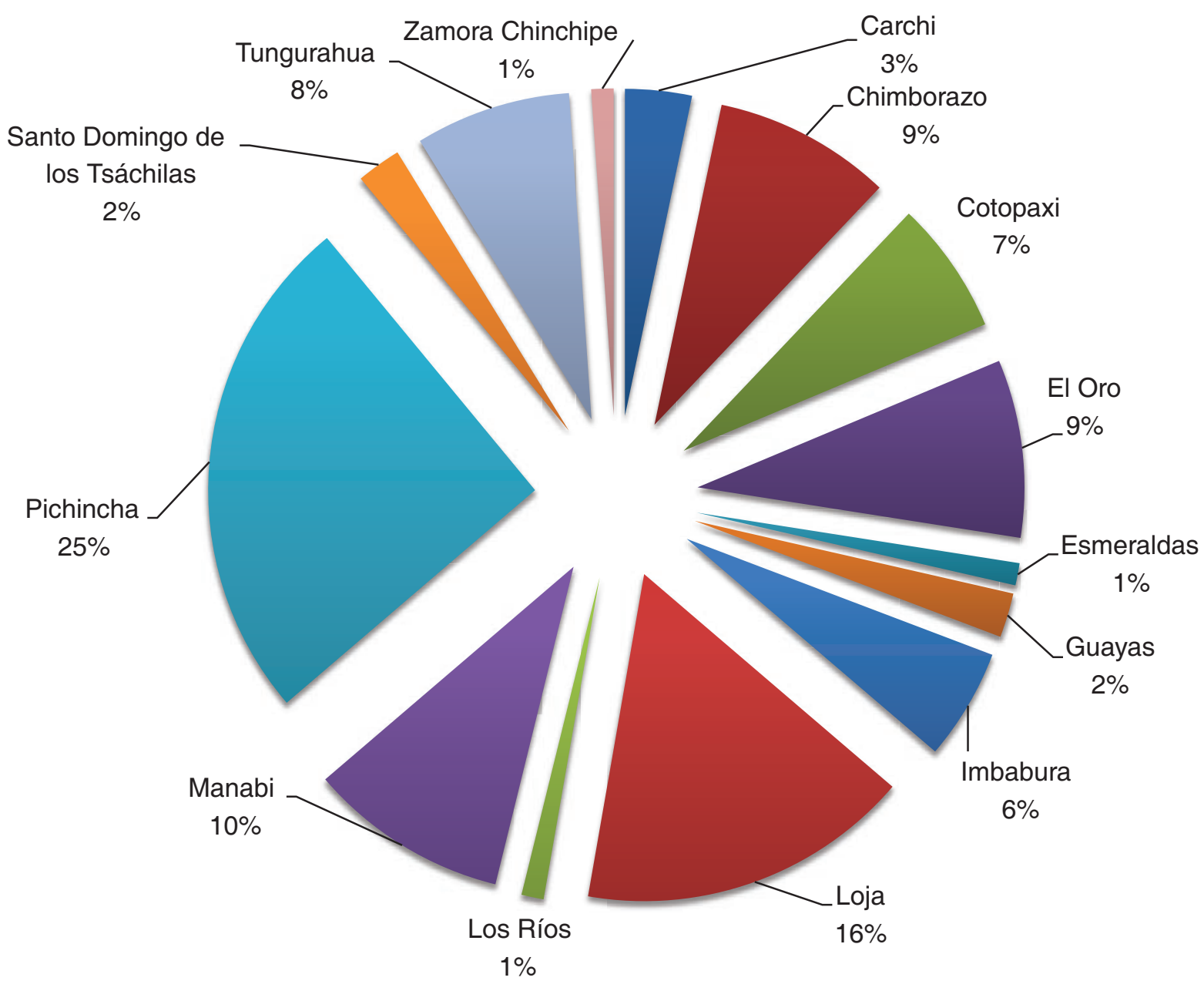

Figure 1. Dia antigens percentage distribution in blood donors according to place of origin. The graph shows the percentage distribution of samples from blood donors according to their place of origin. In all provinces was the existence of Dia-positive donors identified.

as ethnic population and, therefore, the elevated prevalence of $\mathrm{Di}^{\mathrm{a}}$ antigen found in this study might be understood. In addition, said percentage is almost uniformly distributed throughout the national territory, with marked population foci observed in the andean provinces $^{8}$. Thus, in this study, $24 \%$ of donors with positive $\mathrm{Di}^{\mathrm{a}}$ antigen were identified to be found in the province of Pichincha, followed by Loja with $16 \%$, Manabí with $10 \%$, in addition to Chimborazo, Tungurahua and Cotopaxi with a prevalence of 9,8 and $7 \%$, respectively. This corroborates the distribution of this antigen in the andean provinces of the country, with the central mountain range being an important focus of $\mathrm{Di}^{\mathrm{a}}$ antigen distribution.

A relevant finding was the presence of $10 \%$ of Diego antigen in the Manabí province, where 32\% alloimmunization by this antigen was identified, which shows the necessity to include typing tests for the Diego antigen in this province. Other studies claim that the prevalence of $\mathrm{Di}^{\mathrm{a}}$ antigen may be higher in South
American regions; in the Kaingang population, native to the Santo Domingo, Cabo Verde region, in Brazil, prevalence is as high as $45.8 \%$.

Identification and localization of blood donors who are carriers of the Diego antigen is highly useful for blood banks owing to the relationship between this antigen and the production of antibodies that cause post-transfusion hemolytic reactions. The study conducted in Guatemala determined that 3.5\% of polytransfused patients had anti-Dia antibodies. In spite of not causing an immediate severe hemolytic response, it is one of the causes of early post-transfusion reactions, which are difficult to detect, so that a second incompatible transfusion might then cause a severe hemolytic reaction ${ }^{1}$. In this study, the Pichincha province was established to have a higher prevalence of $\mathrm{Di}^{\mathrm{a}}$ antigen with regard to the other provinces, and identification of this antigen should be therefore performed, since this region is the major provider of blood to the country's health centers. 




Figure 2. Percentage of alloimmunized (anti-Dia) donors by province. The graph shows the percentage distribution of donors who were carriers of the Diego alloantibody, with Manabi being found to have the highest prevalence and six provinces were found not to have alloimmunized donors.

Another aspect considered in this investigation was the prevalence of the Diego $\left(\mathrm{Di}^{\mathrm{i}}\right)$ antigen with regard to gender, with a similar distribution being determined between males and females and their age groups. These data constitute relevant information due to the likelihood of alloimmunization in women of childbearing age; even when there is a high prevalence, there is also a percentage of women lacking the antigen, which might cause adverse effects in an incompatible blood transfusion, and even HDNB. Layrisse, Arends and Domínguez were the researchers who identified the first case of HDNB, determining that the child's red blood cells were sensitized by anti-Dia antibodies originating in the mother ${ }^{1,11}$.

Subsequently, the Diego antigen, initially considered to be of low prevalence, was established to have become a "marker of Mongoloid populations with high genetic and anthropologic value"1. Several studies have established that the Diego antigen is part of a red blood cell membrane protein that accounts for $25 \%$ of total red blood protein, and for this reason, today it is one of the antigens that should be identified in populations with high prevalence ${ }^{2}$.

Screening for irregular antibodies or alloantibodies in blood donors is within the guidelines of blood bank standards $^{12}$; however, commercial cells used for this purpose do not detect Diego system alloantibodies ${ }^{13,14}$, since these cells are prepared in countries where Diego antigens are not common, and finding cells with this phenotype is therefore not possible ${ }^{2}$. This is why introducing these reagents is necessary in countries with prevalence of these antigens. This way, in Singapore, the use of $\mathrm{Di}^{\mathrm{a}}$ cells enabled determining the presence of alloimmunization by the Diego system in 19 out of 1,383 samples with inconclusive results in the panel of commercial cells ${ }^{15}$.

Different studies have determined the presence of anti-Dia alloantibodies in blood donors within a range from $0.02 \%$ to $13.0 \%{ }^{16}$. In this investigation, a prevalence of anti-Dia of $6 \%$ was detected in blood donors, whereas in Texas, in the Corpus Christy area, a prevalence of anti-Dia antibodies of $1.3 \%$ was reported in 
individuals with previous transfusions ${ }^{17}$; in Brazil, 112 patients $(3.6 \%)$ with anti-Dia were identified; in Singapore, a prevalence of $1.37 \%$ was determined ${ }^{2,15}$, and in the study carried out in Guatemala, a prevalence of anti-Dia of $3.5 \%$ was found in multi-transfused patients ${ }^{10}$. Anti-Dia antibodies are generally of the immunoglobulin $(\mathrm{Ig}) \mathrm{G} 1$ and $\mathrm{IgG} 3$ types and are related to hemolytic disease of the newborn ${ }^{18}$. In a study carried out in Brazil, the presence of anti-Dia in women was determined to be $1.9 \%$, which entailed risk in case of pregnancy and/or blood transfusion. In that study, Marcondones mentions the presence of two women sensitized by anti-Dia during pregnancy; however, the newborns had no problems, owing to the follow-up throughout the natal period. This reinforces the need for screening to be implemented in countries with Diego antigens prevalence ${ }^{19}$.

The presence of anti-Dia is directly related to transfusional hemolytic reactions. One case reported in 2012 referred the presence of a transfusional reaction in a woman after having received $800 \mathrm{~mL}$ of blood during surgery; pre-transfusion tests had been negative; however, she had symptoms related to hemolysis, with subsequent tests identifying the presence of anti-Di ${ }^{\mathrm{a}}$ alloantibodies ${ }^{14}$.

Finally, inclusion of the Diego system in screening tests for irregular antibodies both in blood donors and multi-transfused patients constitutes an emergent aspect owing to the Ecuadorian population demographic characteristics and to the percentage of unidentified alloantibodies existing in the Ecuadorian Red Cross Blood Center and blood banks that perform these tests, in addition to the fact that commercial cells for screening lack these antigens. Therefore, one recommendation to the national Ecuadorian blood system is to see into changes in the follow-up regulations for pregnant women within the Free Maternity Program, especially in those provinces where the existence of alloantibodies of the Diego system $\left(\mathrm{Di}^{\mathrm{a}}\right)$ were reported.

\section{Conflict of interests}

The authors declare there is no conflict of interests. Funding for this research was granted by the Pontificia Universidad Católica del Ecuador, in its mission to promote research among faculty members.

\section{References}

1. Soyano A. El antígeno Diego alcanza los 60 años de edad: su descubrimiento y desarrollo. Gac Méd Caracas. 2014;122(1):46-52.

2. Daniels G. Diego Blood Group Systems. En: Daniels G. Human Blood Groups. 3. a ed. USA: Wiley-Blackwell; 2013.

3. Park T, Oh SH, Choi CJ, et al. The clinical significance of antibody screening test including Dia+ panel cell in Asian-Mongoloid populations. J korean Med Sci. 2013; 18(5):669-72.

4. Lopez M, Cortina L. Enfermedad hemolítica perinatal. Rev cuba hematol inmunol hemoter. 2000;16(3):161-83

5. Mun S, Lee S. A case of acute hemolytic transfusion reaction due to anti-Dia antibody -A case report. Korean J Anesthesiol. 2012;63(4):353-6.

6. Bhutani VK, Zipursky A, Blencowe $\mathrm{H}$, et al. Neonatal hyperbilirubinemia and rhesus disease of the newborn: incidence and impairment estimates for 2010 at regional and global levels. Pediatric Res. 2013;74(Suppl 1):86-100.

7. Marín Rojas RA, Duarte Sibaja MO. Fenotipos y genotipos del sistema Diego en Costa Rica. Rev costarric cienc méd. 1997;18(3):43-5.

8. Resultados del censo 2010 [Internet]. Ecuador: Instituto Nacional de Estadísticas y Censos. Disponible en: http://www.ecuadorencifras.gob. ec/resultados

9. Wei CT, Al-Hassan F, Naim N, et al. Prevalence of Diego blood group antigen and the antibody in three ethnic population groups in Klang valley of Malaysia. Asian J Transfus Sci. 2013;7(1):26-8.

10. Gutiérrez J, Lanz K, Pérez Minera A, et al. Frecuencia del antígeno Dia en donantes y de anticuerpos anti-Dia en pacientes de Hospitales Públicos y del Instituto Guatemalteco de Seguridad Social. Rev argent transfus. 2013;39(4):255-9.

11. Junqueira P. The history of Diego blood group. Rev Bras Hematol Hemoter. 2002;24(1):15-23.

12. Organización Panamericana de la Salud. Estándares de trabajo para servicios de sangre. 3. ${ }^{a}$ ed. Washington: Organización Panamericana de la Salud; 2011.

13. BIO-RAD. Set DiaPanel:45241.45x. DiaPanel. Switzerland, Cressier.

14. Mun SH, Lee SH, No MY. A case of acute hemolytic transfusion reaction due to anti-Di(a) antibody -A case report-. Korean $\mathrm{J}$ Anesthesiol. 2012;63(4):353-6.

15. Xian EKC, Y. M. To assess the number of cases of anti-Dia in Singapore and its importance to incorporate into antibody screening panel. Transfusion. 2011;51:136A-7A.

16. Garg N, Sharma T, Singh B. Prevalence of irregular red blood cell antibodies among healthy blood donors in Delhi population. Transfus Apher Sci. 2014;50(3):415-7.

17. Thompson C. Diego(a) antigen frequency and anti-Diego(a) frequency in a South Texas community. Clinical Lab Sci. 2006;19(4):203-5.

18. Daniels G, Bromilow I. Essential Guide to Blood Groups. Oxford: Wiley-Blackwell; 2013.

19. Nardozza LM, Camano L, Fernandes Moron A, et al. Anti-Diego alloimmunization: report of two cases. Arch Gynecol Obstet. 2007;275(6):495-7. 